\title{
Parlamentos regionais nas negociações comerciais: o Parlamento Europeu e o do Mercosul no acordo União Europeia-Mercosul
}

\author{
Karina L. Pasquariello Mariano ${ }^{1}$ \\ Bruno Theodoro Luciano ${ }^{2}$ \\ Lucas Bispo dos Santos ${ }^{3}$
}

\begin{abstract}
As negociações Mercosul-UE são tradicionalmente analisadas pela perspectiva dos governos. O objetivo deste artigo é discutir o papel e a relevância dos parlamentos regionais nessas negociações, que perduram mais de 20 anos. A análise verifica se a existência de um parlamento regional amplia as discussões sobre as negociações e influi no andamento destas, considerando o período entre 1999 e 2017. O artigo analisa as posições dos parlamentares em relação às propostas apresentadas pelos respectivos blocos, o nível de informação que os parlamentares possuem sobre as negociações a que têm acesso e a capacidade de influência dos parlamentares regionais nos termos do acordo. $O$ intuito foi verificar o grau de envolvimento dos parlamentos regionais nas negociações comerciais. Concluímos que, embora os dois parlamentos tenham graus de competências bastante distintos, em ambos os casos se observa uma atuação autônoma com relação aos Executivos, que apresenta um importante grau de polarização política em relação aos resultados do acordo e uma forte demanda por negociações comerciais mais transparentes.

Palavras-chave: negociações comerciais; União Europeia; Mercosul; parlamento europeu; parlamento do Mercosul
\end{abstract}

\section{Introdução}

As negociações comerciais são tradicionalmente analisadas pela perspectiva dos governos, partindo da suposição de que estes são porta-vozes dos interesses nacionais. Algumas pesquisas apresentam análises mais amplas, levando em consideração os grupos de interesse que pressionam os governos ou as instâncias burocráticas internas que podem interferir no posicionamento dos representantes governamentais (Silva-Rêgo, Figueira, 2018; Mariano e Ramanzini Jr., 2013). Contudo, dificilmente se analisa a participação dos

1 Unesp, Departamento de Antropologia, Política e Filosofia. Araraquara (SP), Brasil. E-mail: $<$ karinapmariano@gmail.com>.

2 University of Birmingham, Political Science and International Studies. Birmingham (WM), Reino Unido. Email: <brutheodoro@hotmail.com>.

3 Programa Interinstitucional de Pós-Graduação em Relações Internacionais San Tiago Dantas

(PUC-SP, Unesp e Unicamp), São Paulo (SP), Brasil. E-mail: <lucasbispoo18@gmail.com>. 
PARLAMENTOS REGIONAIS NAS NEGOCIAÇÕES COMERCIAIS: O PARLAMENTO EUROPEU E DO MERCOSUL

parlamentos regionais nas negociações comerciais. Este artigo discute justamente o papel e relevância dos parlamentos regionais nessas negociações, usando como objeto de análise o caso das negociações do acordo entre União Europeia (UE) e Mercado Comum do Sul (Mercosul), que perduram mais de 20 anos. Nossa argumentação se baseia na seguinte questão: a existência de um parlamento regional ampliou as discussões sobre as negociações e influiu no andamento destas?

Como essa negociação envolve dois parlamentos regionais muito distintos, buscamos responder à pergunta considerando as particularidades de cada caso. Considerando que o Parlamento Europeu (PE) ao longo do tempo alcançou competências mais próximas de um parlamento nacional (Kreppel, 2002; Rittberger, 2003; Campos, 2017) e que o Parlamento do Mercosul (Parlasul) mantém-se como esfera consultiva do Mercosul (Dri e Paiva, 2016; Mariano, Bressan e Luciano, 2017), este artigo discute em que medida possuir maior capacidade de poder decisório - como no caso do PE - é um elemento que influencia no envolvimento parlamentar em negociações comerciais.

Apesar das claras diferenças em termos de competências e desenvolvimento institucional entre os dois casos, consideramos que a UE não é necessariamente um modelo sui generis $(n=1)$, como parte da literatura havia anteriormente defendido (Caporaso et al., 1997; Phelan, 2012). Na verdade, nos alinhamos com a emergente agenda de pesquisa sobre regionalismo comparado, que tem argumentado que o caso europeu pode ser, em determinados aspectos, contrastado com outras organizações regionais estabelecidas majoritariamente na América Latina e na África (Söderbaum, 2015; Börzel e Risse, 2016). Tendo em vista que os dois casos parlamentares analisados neste artigo foram instâncias criadas dentro de organismos com vocação para integração regional com o intuito de acrescer legitimidade democrática às decisões tomadas em nível regional, ambos buscaram igualmente monitorar e participar de temas decididos no âmbito de seus blocos regionais. Essa tendência pode inclusive ser observada no campo das negociações comerciais, tema tradicionalmente conduzido no âmbito do Mercosul e da UE. Nesse sentido, desenvolver um esforço comparado para analisar o papel dos parlamentos regionais em negociações comerciais é fundamental para alcançar um melhor entendimento sobre em que medida essas e outras instâncias parlamentares têm contribuído para politizar e democratizar os acordos comerciais firmados pelos blocos regionais.

Na primeira parte do artigo, "O desenvolvimento das negociações comerciais Mercosul-UE: origens, estagnação e relançamento", recuperamos as linhas gerais do histórico da relação entre UE e Mercosul, apresentando os principais momentos da negociação e as propostas defendidas por ambos os lados. Em seguida, em "O Parlamento Europeu nas negociações Mercosul-UE: autonomia, transparência e polarização", verificamos o envolvimento do Parlamento Europeu (PE) nas negociações de políticas comerciais, partindo do questionamento acima apresentado. Na terceira parte, "O Parlamento do Mercosul nas negociações Mercosul-UE: autonomia, transparência e polarização", abordamos o caso do Mercosul, apresentando quais os aspectos semelhantes 
e divergentes encontrados em relação ao caso europeu no acompanhamento parlamentar das negociações do referido acordo.

Além de analisarmos os instrumentos utilizados nos dois casos parlamentares, para influir ou se posicionar a respeito das negociações, observamos também o conteúdo dos documentos e das discussões parlamentares nos últimos anos a partir do conteúdo disponível nas páginas eletrônicas de ambos os parlamentos ${ }^{4}$. Em cada caso, três elementos foram observados: o grau de autonomia dos parlamentos frente às posições dos Executivos, o nível de transparência das negociações e a polarização política em cada parlamento regional com relação ao acordo comercial.

Finalmente, na conclusão comparamos as posições dos parlamentares em relação às propostas apresentadas pelos respectivos blocos, o grau de informação sobre as negociações a que têm acesso efetivamente e a capacidade de influência dos parlamentares regionais nos termos do acordo. Argumentamos que, embora os dois parlamentos regionais apresentem competências distintas com relação a seu papel formal nas negociações comerciais de seus blocos, em ambos os casos se observam uma atuação autônoma em relação à posição negociadora dos executivos regionais, uma preocupação em acessar as informações das negociações e um nível de polarização política a respeito do acordo birregional; mais acentuado no caso europeu.

\section{O desenvolvimento das negociações comerciais Mercosul-UE: origens, estagnação e relançamento}

A ideia de um acordo entre a União Europeia e o Mercosul emergiu um mês após a criação do Mercosul em abril de 1991, quando os chanceleres desse bloco expressaram ao presidente da Comissão Europeia seu interesse em estabelecer um acordo de cooperação institucional, o qual não envolveria temas comerciais naquele momento. Essa primeira aproximação buscava legitimar o processo e fortalecer sua posição diante das pressões advindas do governo norte-americano que havia proposto a Iniciativa para as Américas (Amorim e Pimentel, 1996; Mariano, 2015).

O tema "comércio" apareceu na agenda das relações Mercosul-UE no final de 1994, simultaneamente ao início das negociações da Área de Livre Comércio das Américas (Alca). Um ano depois, o Acordo-Quadro de Cooperação Inter-Regional Mercosul-UE seria assinado, tendo sido o primeiro acordo entre os dois blocos com o objetivo de estabelecer uma área de livre comércio até 2005. As negociações, no entanto, foram iniciadas apenas a partir de 1999.

Uma rede de interesses se desenhava dos dois lados do Atlântico. A Europa

\footnotetext{
4 Para o Parlamento Europeu, os documentos foram retirados no website:

<http://www.europarl.europa.eu/committees/en/search-in-documents.html>; no caso do Parlasul, as informações foram obtidas na base de notícias:

<https://www. parlamentomercosur.org/innovaportal/v/13215/1/parlasur/noticias.html>. Acesso em: 26 mar. 2018.
} 
procurava aumentar a competitividade do bloco nos mercados externos, em um contexto no qual os EUA saíam como única superpotência no cenário pós-Guerra Fria. Um acordo com os países mercossulinos permitiria a importação a custos menores de matériasprimas, produtos intermediários e componentes para suas indústrias. Ao mesmo tempo, enxergava o crescente mercado sul-americano como profícuo para reforçar a posição das empresas europeias na região e permitir a instalação de novas companhias, visando à modernização das plantas industriais dos países e à compra de serviços do continente para melhorias de infraestrutura. Portanto, há evidente foco do lado europeu no setor industrial, de serviços e em compras governamentais (Comissão Europeia, 2014; Cienfuegos, 2006).

O Mercosul, por sua vez, tinha grande interesse na abertura do protegido mercado europeu para seus produtos agrícolas, o que estimularia o crescimento econômico baseado no aumento das exportações (Cienfuegos, 2006). De forma concomitante, as negociações com a UE poderiam permitir que o bloco do Cone Sul ganhasse poder de barganha ao gerar negociações em três frentes: Mercosul-UE, Rodada Doha da Organização Mundial do Comércio (OMC) e negociações da Alca, que, em boa medida, ditaram as dinâmicas entre UE e Mercosul (Boyer e Schuschny, 2010).

As negociações entre os dois blocos regionais sofreram diversos reveses ao longo do tempo. A crise experimentada pelo Mercosul desde 1998 e a sua incapacidade de coordenar posições governamentais impediram o progresso das negociações (Ventura, 2003). Em julho de 2001, durante a quinta rodada de negociações entre UE e Mercosul, a delegação europeia apresentou sua oferta tarifária e não tarifária, enquanto os países do Mercosul não realizaram sua parte, porque o governo argentino enfrentava dura crise política e econômica, inclusive ameaçando sair do Mercosul.

A oferta europeia representou a disposição em manter as negociações ativas e a intenção da UE de não ficar para trás nas negociações comerciais lideradas pelos Estados Unidos. Conforme mencionado por Chris Patten, Comissário Europeu de Relações Exteriores, em novembro de 2000, "We have a huge interest in this agreement with Mercosur, so as not to lose space for the United States, as happened in Mexico" (apud Savini, 2001, p. 110). No entanto, ao mesmo tempo, a UE revelava seus próprios problemas: a Política Agrícola Comum (PAC) definia-se como maior obstáculo às negociações.

A falta de consenso entre os governos não era um problema apenas no Mercosul. Em 1997, quando a Comissão Europeia solicitou o mandado para as negociações, vários países expressaram sua oposição, com a França liderando esse movimento. O ponto principal era o temor dos potenciais danos aos produtores agrícolas europeus em face da livre competição com os países do Mercosul. Naquele momento, Espanha, Suécia e Finlândia eram favoráveis a amplas negociações multilaterais por meio dos mecanismos da OMC. A delegação francesa, por sua vez, demandava que os assuntos comerciais fossem tratados com o Mercosul apenas em 2003, quando entendia-se que a Rodada da OMC estaria finalizada (Savini, 2001, p. 114). 
As negociações Mercosul-UE perderam fôlego com as mudanças ocorridas no cenário mundial e com o fracasso das negociações na OMC e na Alca. No primeiro caso, a partir dos atentados de 11 de setembro nos EUA, a agenda internacional se modificou. Temas de segurança e combate ao terrorismo se tornaram centrais tanto para os Estados Unidos quanto para a Europa (Saraiva, 2004; Valle, 2005). Portanto, o comércio perdeu importância estratégica para a política externa americana, levando a diversos impasses nas negociações multilaterais, incluindo-se a Rodada Doha da OMC e outras negociações comerciais como a Alca. Ademais, a crise econômica global de 2008 acentuou essas dificuldades, tendo em vista que os países da UE tiveram de enfrentá-la simultaneamente aos efeitos de implementação da Zona do Euro e das ondas de alargamento do bloco, sem mencionar o desapontamento político devido à rejeição do projeto de Constituição Europeia. Todos esses problemas desviaram a atenção europeia e levaram as negociações com o Mercosul para um plano secundário (Tomazini, 2011; Flôres, 2003).

Outro importante fator para o impasse nas negociações Mercosul-UE foi a emergência da China como importante parceiro comercial e investidor nos países em desenvolvimento (Deutsche Bank, 2011; Kegel e Amal, 2013). Desde 2005, a cooperação Sul-Sul tornou-se meta primordial para os países do Mercosul, especialmente para o Brasil. Nesse caso, a parceria com países como Rússia, Índia, China e África do Sul (conhecidos pelo acrônimo Brics) e a criação da União das Nações Sul-Americanas (Unasul) tornaramse aspectos centrais da política externa brasileira (Hirst, Lima e Pinheiro, 2010).

Em maio de 2010, os governos buscaram relançar as negociações Mercosul-UE, em um momento de diversas mudanças na Europa, principalmente devido à implementação do Tratado de Lisboa, o qual alterou substancialmente o papel de instituições como o Parlamento Europeu nas negociações internacionais. Além disso, o bloco já havia acomodado os impactos resultantes dos alargamentos ocorridos em 2004 e 2007, nos quais 12 novos Estados membros foram incorporados à UE.

Do lado do Mercosul, o contexto político também parecia favorável à retomada das negociações. Naquele período, a economia brasileira continuava a crescer fortemente, o que também estimulava o crescimento regional e parecia levar a uma redução da resistência argentina às negociações. Ao mesmo tempo, houve certa preocupação em acelerar as negociações antes da incorporação completa da Venezuela ao Mercosul, tendo em vista que a presença de Hugo Chávez representaria um elemento de desestabilização nas negociações entre os dois blocos.

A conjuntura regional favorável começou a perder força após a morte do expresidente argentino Néstor Kirchner (outubro de 2010), que provocou um abalo da base governista devido à disputa interna referente às eleições de 2011, nas quais a presidente Cristina Kirchner foi reeleita com um discurso de reafirmação de uma lógica nacionalprotecionista, menos aberta a negociações econômicas com países desenvolvidos. A ascensão de Dilma Rousseff em 2011 também contribuiu para a redução das chances de avanço das negociações birregionais, pois, diferentemente de seu antecessor, a nova 
presidente do Brasil não apresentou o carisma e a liderança necessários para manter as diretrizes externas implementadas por Lula da Silva. O Brasil gradualmente retraiu sua presença na região e o Mercosul novamente entrou em um período de negociações estagnadas, o qual impactou negativamente a condução das negociações com a UE.

Contudo, em 2015 alterou-se a lógica protecionista da política externa argentina, com a vitória nas eleições presidenciais de Maurício Macri, que apresentou um discurso altamente favorável à liberalização comercial e posicionou a retomada das negociações com a UE como prioridade. Sua influência na posição do governo brasileiro de Michel Temer (sucessor de Dilma Rousseff) é inegável, incluindo suas intenções de aproximação com os países da Aliança do Pacífico, os Estados Unidos (ainda durante a administração Obama) e, obviamente, a UE. Há, portanto, nova disposição nas posturas dos países do Mercosul em aceitar a concretização do acordo, diferentemente de períodos anteriores, em que as hesitações por parte dos Executivos eram maiores. Essas mudanças políticas na região foram importantes para o aumento de apoio político às negociações com a UE. Os novos governos da região têm mostrado seu comprometimento com uma política externa não necessariamente enfocada nas relações Sul-Sul, pois sua preocupação central está na realização de acordos comerciais com os parceiros tradicionais: reaproximação com os Estados Unidos e concretização do acordo de associação Mercosul-UE.

Desde 2015 esse cenário tem se modificado e uma nova conjuntura parece aumentar os interesses nas retomadas do acordo Mercosul-UE. Do lado europeu, a ameaça britânica de sair da UE - concretizada pelo referendo de 2015 - deu novo impulso à conclusão de negociações comerciais. Ademais, esse contexto de insegurança econômica aumentou a partir da eleição de Donald Trump nos Estados Unidos e sua visão negativa em relação ao Acordo Transatlântico de Comércio e Investimento (TTIP).

Portanto, depois de mais de duas décadas de negociações, representantes dos dois blocos anunciaram a retomada do diálogo comercial em abril de 2016, a qual efetivamente ocorreu um mês depois, quando novamente realizaram trocas de ofertas tarifárias. Desde então as discussões têm se movido rapidamente apesar de as perspectivas de atingir esse objetivo serem cada vez mais remotas, tendo em vista as mudanças políticas na Europa e na América do Sul.

Diante dessa mais recente conjuntura, analisamos nas próximas seções o comportamento dos parlamentos regionais nessas negociações e a sua participação no processo, buscando verificar se a capacidade de influir no poder decisório interfere no desempenho desses atores e qual a extensão dessa interferência. Esse argumento foi medido a partir de três elementos: o grau de autonomia em relação aos Executivos, o nível de transparência das negociações e a polarização política em relação ao acordo comercial. 


\section{O Parlamento Europeu nas negociações Mercosul-UE: autonomia, transparência e polarização}

Esta seção analisa o envolvimento do Parlamento Europeu (PE) no diálogo comercial com o Mercosul. Não somente são observados os espaços e instrumentos que o Parlamento utilizou para participar das negociações, como também o seu posicionamento político em relação ao acordo de associação, em contraste com as posições tanto da Comissão Europeia (CE) quanto dos Estados membros. Conforme explicitado, três aspectos são enfatizados nesta análise: o grau de autonomia dos eurodeputados quanto a suas opiniões nas negociações, o nível de transparência e acesso às informações dos parlamentares acerca dos termos e estágios do acordo comercial, e finalmente a escala de polarização dos debates referentes à condução desse acordo.

No que diz respeito ao acordo de associação Mercosul-UE, o PE tem concentrado suas ações em duas instâncias: na Comissão de Comércio Internacional (Inta) e na delegação do PE para as relações com os países do Mercosul. Inta é a instância-chave na qual os eurodeputados supervisionam as negociações externas da UE, e o acordo com o Mercosul não é uma exceção. Assim como o monitoramento de outros acordos comerciais europeus, os membros da Inta solicitam ao longo do tempo maiores informações sobre o estágio e o conteúdo das negociações Mercosul-UE para a Comissão Europeia, responsável pela condução das negociações, e demonstram sua preocupação ou apoio em relação ao andamento do diálogo comercial.

A Delegação para as relações com os países do Mercosul (D-MER) é outro importante canal de diálogo parlamentar entre a UE e o Mercosul. Assim como outras delegações do PE para as relações com os países ou regiões da América Latina (Stavridis e Ajenjo, 2010), a Delegação para o Mercosul é majoritariamente composta por membros com laços históricos e linguísticos dos seus membros, com importante presença de eurodeputados portugueses e espanhóis. Essa delegação parlamentar é principalmente responsável por impulsionar a diplomacia parlamentar entre o PE e as classes políticas dos países do Mercosul. Além disso, o acordo de associação Mercosul-UE em andamento também está no centro desse diálogo político-partidário.

Nesse sentido, membros dessa delegação se reuniram com o então presidente do Paraguai, Fernando Lugo, em 2011 e discutiram o futuro das negociações entre UE e Mercosul, levando em consideração o impasse das negociações naquele momento e a sensibilidade dos lados europeu e mercossulino nas negociações (Parlamento Europeu, 2011). Portanto, apesar de o monopólio da condução dessas negociações estar nas mãos da CE, o PE pode ser um agente importante nesse diálogo, facilitando e intensificando os laços políticos entre os dois lados. Em 2015 - seguindo a consolidação da Parceria Estratégica Brasil-União Europeia e devido ao apoio dos deputados portugueses - o PE estabeleceu uma delegação para as relações com o Brasil, na qual os debates sobre as 
negociações Mercosul-UE também podem eventualmente ocorrer ${ }^{5}$. Ademais, esse Parlamento tem empregado instrumentos específicos para se engajar nas negociações Mercosul-UE. Dois em particular devem ser destacados: as resoluções parlamentares e as questões/debates envolvendo a Comissão Europeia. Em primeiro lugar, as resoluções têm sido frequentemente usadas pelo PE como um instrumento formal para publicizar a opinião da maioria dos eurodeputados com relação ao andamento das negociações entre os dois blocos. Com relação ao acordo Mercosul-UE, duas resoluções do PE foram identificadas entre 2006 e 2013, ambas aprovadas antes da assinatura do Tratado de Lisboa e do empoderamento parlamentar nas políticas comerciais da UE. De modo geral, os dois textos parlamentares foram muito favoráveis à conclusão do acordo. Embora reconheçam a importância do acordo Mercosul-UE, os eurodeputados lamentam o ritmo lento destas, assim como enfatizam a necessidade de inserir maiores referências a temas de direitos humanos e democracia no cerne das negociações. Em ambas as resoluções, o PE não ditou nenhum limite (red line) às negociações, embora reconheça e faça menção a setores sensíveis como a agricultura. Mais importante, esses documentos demonstram que o PE apresenta uma posição autônoma perante a Comissão acerca do acordo birregional.

Alguns assuntos, como direitos humanos e proteção ao setor agrícola, são considerados particularmente importantes para o Parlamento. Assim, as resoluções parlamentares são instrumentos que reforçam e publicizam para as demais instituições europeias a opinião do Parlamento sobre o mandato e o progresso das negociações comerciais. Em um contexto pós-Tratado de Lisboa, é vital que a Comissão e o Conselho levem em consideração a posição do $P E$ nas negociações, já que uma divergência significativa nos termos do acordo pode levar a um possível veto parlamentar a este.

Outro meio utilizado pelo PE de se fazer mais presente nas negociações comerciais é apresentar questões parlamentares à Comissão e convidar seus membros para debates públicos, com o intuito de obter maiores informações a respeito do estágio do acordo. Os eurodeputados, ao longo dos últimos anos, têm enviado à Comissão questões acerca de alguns aspectos das negociações Mercosul-UE. Interessante notar que a maioria dessas questões relaciona-se ao setor agrícola 6 . Ademais, uma das perguntas foi se a Parceria Estratégica Brasil-UE poderia impactar as negociações do acordo Mercosul-UE7. Ressaltamos que essas questões, que devem receber resposta oral, podem também

\footnotetext{
5 Para mais informações sobre a delegação para as relações com o Brasil do PE, ver: <http://www.europarl.europa.eu/delegations/en/d-br/home.html>. Acesso em: 26 mar. 2018.

6 Questões sobre agricultura e Acordo Mercosul-UE (2010). Disponível em: $<$ http://www.europarl.europa.eu/sides/getDoc.do?type=OQ\&reference=0-2010-

0079\&format $=X M L \&$ language $=E N>$; Questões sobre Mercosul-UE e agricultura (2010). Disponível em: $<$ http://www.europarl.europa.eu/sides/getDoc.do?type=OQ\&reference=0-2010-

0067\&format $=X M L \& l a n g u a g e=E N>$; Questões sobre AA com Mercosul e agricultura (2016). Disponível em: $<$ http://www.europarl.europa.eu/sides/getDoc. do?type=WQ\&reference=E-2016009002\&format=XML\&language =EN>. Acesso em: 26 mar. 2018.

7 Questionamento se a parceria estratégica Brasil-UE poderia impactar nas negociações do acordo MercosulUE (2007). Disponível em: <http://www.europarl.europa.eu/sides/getDoc.do?type=OQ\&reference=0-20070056\&format $=X M L \& l a n g u a g e=E N>$. Acesso em: 26 mar. 2018.
} 
produzir uma repercussão mais forte e levar a um debate parlamentar que tenha a presença de membros da Comissão responsáveis pelo acordo. Esse foi o caso de uma questão oral levantada em $2010^{8}$, a qual moveu um debate parlamentar com o então comissário de Comércio Karel de Gucht.

Mais recentemente, em 2016, outra questão para resposta oral ${ }^{9}$ foi apresentada por membros da Inta, levando à realização de um debate público organizado no dia 10 de maio com a participação da comissária de Comércio Cecilia Malmström. Esses debates são momentos importantes em que os parlamentares europeus podem questionar abertamente a Comissão sobre o conteúdo e o progresso das negociações comerciais, apresentando sua posição em relação ao acordo, assim como suas preocupações centrais, as quais não são necessariamente compartilhadas pelos representantes da Comissão Europeia. Transparência é outro assunto-chave para o envolvimento parlamentar nas negociações comerciais. Como uma das principais funções do PE é supervisionar as atividades da Comissão, o Parlamento necessita acessar informações suficientes para garantir a qualidade e a correção do desempenho do Executivo europeu. Nesse contexto, o relatório do PE de 2016 sobre políticas comerciais da UE faz referência à demanda parlamentar por maior acesso às informações sobre as negociações. Também considera que as negociações com os Estados Unidos (TTIP) foram inovadoras com relação ao método de escrutínio parlamentar desse diálogo comercial. Conforme registrado por uma carta do PE endereçada à Comissão de Comércio:

We are confident that these arrangements increase transparency of TTIP negotiations even further with respect to the European Parliament. The respect of these arrangements is important for the European Parliament to carry out its responsibilities under EU Trade Policy without jeopardising the interests of the Union, thereby, strengthening democratic scrutiny and accountability of the EU Trade Policy. Ultimately, these arrangements contribute to foster legitimacy of the EU Trade Policy (Parlamento Europeu, 2015 , p. 2).

Portanto, esse fato criou uma expectativa de que as atuais e futuras negociações da Comissão seguiriam os mesmos procedimentos definidos pelo acordo transatlântico. Com relação às negociações Mercosul-UE, entretanto, observa-se uma forte crítica dos parlamentares ao acesso aos termos das negociações. Uma questão parlamentar ${ }^{10}$ ao Conselho em 2016 foi se o mandato negociador para o acordo Mercosul-UE - o qual foi

\footnotetext{
${ }^{8}$ Questão oral para a Comissão (4 de junho de 2010). Disponível em:

$<$ http://www.europarl.europa.eu/sides/getDoc.do?type=0Q\&reference=0-2010-

0079\&format $=X M L \&$ language $=E N>$. Acesso em: 26 mar. 2018.

${ }^{9}$ Questão oral para a Comissão (16 de março de 2016). Disponível em:

$<$ http://www.europarl.europa.eu/sides/getDoc.do?type=OQ\&reference=0-2016-000046\&language $=E N>$.

Acesso em: 26 mar. 2018.

10 Disponível em: <http://www.europarl.europa.eu/sides/getDoc. do?type=WQ\&reference=E-2016-

009155\&format=XML\&language =EN >. Acesso em: 26 mar. 2018.
} 
definido em 1999 - seria atualizado de acordo com os princípios da UE revistos pelo Tratado de Lisboa. Ademais, o Parlamento questionou: "To allow the EU institutions to embark up and maintain a deep and informed dialogue with the public and civil society organisations in both regions, could the Council say when it plans to publish the contents of this negotiating mandate?" (Parlamento Europeu, 2016, p. 1). Entrevistas com oficiais e eurodeputados também apontaram que, em comparação às negociações do TTIP, na qual o PE teve acesso a uma sala de leitura com os documentos da negociação classificados, as negociações Mercosul-UE até o momento foram mais obscuras aos parlamentares e à sociedade civil, embora esse diálogo já esteja sendo conduzido por quase duas décadas. Por outro lado, os desenvolvimentos recentes das negociações e a última troca de ofertas tarifárias realizada podem ser uma oportunidade para o crescimento do envolvimento parlamentar nos termos da negociação comercial.

Esse último aspecto é importante porque, na medida em que as negociações parecem avançar para uma conclusão, aumentam a preocupação e a mobilização dos parlamentares em relação aos conteúdos do acordo, já que os compromissos assumidos devem ser implementados, e, ao mesmo tempo, a proximidade do fim das negociações limita a capacidade de barganha dos deputados. Nesse sentido, há uma tendência de radicalização das posições e dos debates, influindo no grau de polarização destes.

A polarização do PE em acordo comerciais é o terceiro aspecto considerado nesta análise e, especificamente no acordo Mercosul-UE, pode ser observado não no conteúdo das resoluções aprovadas - o qual supostamente deve refletir a posição genérica do PE sobre as negociações - mas nos detalhes dos debates e posições parlamentares associados à aprovação das resoluções parlamentares. Por exemplo, em 2006 o Parlamento aprovou uma resolução assumindo sua visão acerca da conclusão do acordo de associação. Essa resolução foi muito favorável à conclusão do acordo. "(...) Stresses that the conclusion of an Association Agreement between the EU and Mercosur, establishing the largest interregional FTA in the world, is a priority strategic objective for the EU's external relations" (Parlamento Europeu, 2006, p. 3).

Contudo, ao investigar o conteúdo do debate associado a essa resolução e particularmente à explicação dos votos de alguns eurodeputados, observa-se claramente que não houve consenso sobre a posição descrita na resolução. Alguns parlamentares especialmente de extrema-direita e extrema-esquerda - opuseram-se a esse documento e ao acordo de associação, enfatizando os perigos de liberalização do mercado agrícola europeu, assim como condenaram a marginalização de assuntos de direitos humanos nessa negociação ${ }^{11}$. Mais interessante ainda é analisar a resolução parlamentar sobre o acordo Mercosul-UE discutida em 2012 e aprovada em 2013, quando alguns grupos políticos europeus apresentaram propostas distintas de resolução, embora tivessem

11 Explanações sobre os votos dessa resolução parlamentar estão disponíveis em: $<$ http://www.europarl.europa.eu/sides/getDoc.do?type=CRE\&reference $=20061012$ \&secondRef $=$ ITEM008\&language $=E N \&$ ring $=A 6-2006-0302 \# 4-148>$. Acesso em: 26 mar. 2018. 
chegado a uma moção conjunta ao final das deliberações. Nesse sentido, os seguintes grupos políticos europeus apresentaram moções de resoluções distintas: liberais; democratas-cristãos junto com os conservadores; socialistas; Esquerda Unida Europeia; e os verdes ${ }^{12}$. Esses documentos apresentaram nuances importantes sobre o conteúdo e a opinião acerca do acordo em negociação com os países do Mercosul. Enquanto a maioria das moções apoiava a condução das negociações, os documentos da Esquerda Unida e dos verdes eram mais críticos quanto ao acordo, especialmente preocupados com os princípios liberalizantes e a crescente exportação latino-americana de bens primários - sobretudo produtos agrícolas - ao mercado europeu. Consequentemente, os liberais, democratascristãos, conservadores e socialistas apresentaram uma moção conjunta ${ }^{13}$, a qual foi finalmente aprovada pela maioria do Parlamento, enquanto as moções apresentadas pelos verdes e pela extrema-esquerda foram vencidas. Além disso, o recente debate parlamentar com a Comissão de Comércio sobre o acordo Mercosul-UE é outra evidência da polarização das políticas comerciais da UE através do envolvimento parlamentar ${ }^{14}$. Novamente, os mesmos padrões de polarização são identificados: enquanto os parlamentares democratascristãos, conservadores, liberais e alguns socialistas apoiaram fortemente as negociações, os eurodeputados da extrema-esquerda e extrema-direita criticaram as negociações comerciais, destacando as possíveis ameaças da liberalização do mercado agrícola. Todavia, a proeminência de interesses nacionais também foi detectada, a saber, parlamentares franceses e irlandeses de diferentes agrupamentos políticos se posicionaram contra o acordo no debate parlamentar de 2016, defendendo a proteção dos setores agrícola e de carne bovina europeus. Em resumo, todos esses episódios demonstram quão polarizados são os debates parlamentares e as deliberações sobre as negociações Mercosul-UE. Em contraste com a perspectiva mais técnica e pragmática da Comissão Europeia, os parlamentares apresentam maior divergência de opiniões sobre essas negociações, levando-se em consideração não somente sua ideologia e seu agrupamento político, como também as posições defensivas de alguns países ou setores, como a agricultura. Enquanto os grupos políticos liberais, conservadores e democratas-

\footnotetext{
12 Resolução do Parlamento Europeu sobre negociações entre UE e Mercosul (2012) - EPP and ECR. Disponível em: <http://www.europarl.europa.eu/sides/getDoc.do?type=MOTION\&reference=B7-20130009\&format $=X M L \& l a n g u a g e=E N>$; Resolução do Parlamento Europeu sobre negociações entre UE e Mercosul (2012) - Green/ALE Group. Disponível em: <http://www.europarl.europa.eu/sides/getDoc.do?type=MOTION\&reference=B7-2013-

0019\&format $=X M L \&$ language $=E N>$; Resolução do Parlamento Europeu sobre negociações entre UE e $\begin{array}{lllll}\text { Mercosul (2012) - } & \text { Alde. Disponível }\end{array}$ $<$ http://www.europarl.europa.eu/sides/getDoc.do?type=MOTION\&reference=B7-2013-

0008\&language=EN>; Resolução do Parlamento Europeu sobre negociações entre UE e Mercosul (2012) S\&D. Disponível em: <http://www.europarl.europa.eu/sides/getDoc.do?type=MOTION\&reference=B72013-0017\&language $=\mathrm{EN}>$. Acesso em: 26 mar. 2018.

13 Moção Conjunta - Resolução do Parlamento Europeu sobre negociações entre UE e Mercosul (2012). Disponível em: <http://www.europarl.europa.eu/sides/getDoc.do?type=MOTION\&reference=P7-RC-20130008\&language $=\mathrm{EN}>$. Acesso em: 26 mar. 2018.

14 Debate - Acordo Mercosul-UE (2016). Disponível em: <http://www.europarl.europa.eu/sides/getDoc.do?type=CRE\&reference=20160510\&secondRef $=$ ITEM013\&format $=X M L \& l a n g u a g e=E N>$. Acesso em: 26 mar. 2018.
} 
cristãos são majoritariamente favoráveis aos acordos comerciais, a Esquerda Unida e os verdes são mais resistentes a eles, os socialistas normalmente se situam em uma posição intermediária (Van den Putte, De Ville e Orbie, 2014; Shaohua, 2015). Além disso, temas relacionados à transparência e ao acesso à informação dos parlamentares persistem, apesar do fato de que o consentimento parlamentar é requerido aos acordos comerciais desde a entrada em vigor do Tratado de Lisboa.

\section{O Parlamento do Mercosul nas negociações Mercosul-UE: autonomia, transparência e polarização}

O Parlamento do Mercosul foi criado no ano de 2005, tendo como seu embrião institucional a Comissão Parlamentar Conjunta (CPC), instalada no âmbito do Mercosul no momento da criação do bloco. Entre seus propósitos estão a representação dos povos do Mercosul e a garantia da participação dos atores da sociedade civil no processo de integração (Mariano, Bressan e Luciano, 2016, 2017; Parlamento do Mercosul, 2005). Nesse sentido, é compreensível que o Parlamento do Mercosul (Parlasul) procure acompanhar as negociações entre Mercosul e UE. A análise do envolvimento do Parlasul nas negociações é feita a partir de duas perspectivas: dos instrumentos utilizados pelo parlamento para se inserir nas conversas entre os blocos e de sua posição política sobre o andamento destas. Levamos em consideração os mesmos aspectos usados para o caso europeu: o grau de autonomia do parlamento e de seus membros em sua opinião sobre as negociações, o nível de transparência e do acesso à informação que o parlamento e seus membros possuem e os níveis de polarização dos debates sobre as negociações.

Diferentemente de seu equivalente europeu, o Parlasul apresenta menor capacidade de pressão institucional ante a estrutura do Mercosul nos processos de tomada de decisão do bloco, uma vez que é um órgão de caráter consultivo, cuja participação não é obrigatória no processo decisório (Mariano, Bressan e Luciano, 2017). Tendo em vista esse ponto, os instrumentos utilizados pelos membros parlamentares se baseiam, sobretudo, nos atos do parlamento previstos em seu Protocolo Constitutivo, como as Declarações e Recomendações.

Analisando os documentos produzidos pelo Parlasul, percebe-se que os debates relativos às negociações Mercosul-UE apareceram de três maneiras. A primeira, através da demanda dos próprios membros parlamentares, seja por meio de pedidos de informes sobre o andamento das negociações ou de recomendações para que elas avancem ou que sejam reativadas - quando estavam paralisadas. A segunda maneira em que o debate aparece é quando esse tema está relacionado a outras negociações internacionais ou questões internacionais, como é perceptível nas discussões relativas à OMC ou às Ilhas Malvinas, que serão retomadas ao longo da seção. A terceira via, por fim, é a do debate sobre o próprio processo de integração do Mercosul, por exemplo, nas discussões relativas à flexibilidade ou à rigidez das negociações internacionais em bloco, no aprofundamento 
institucional do bloco e nas relações de alto nível entre seus órgãos.

No caso da primeira via, o discurso dos parlamentares é orientado, primeiramente, no sentido de terem acesso às informações, evocando a necessidade de transparência das negociações e também procurando incorporar o Parlamento ao processo negociador. $O$ problema da falta de informação parece recorrente, pois em vários momentos encontramos nos registros das Atas do Parlasul pedidos de informes e recomendações ao Conselho do Mercado Comum (CMC) sobre a transparência das negociações. Por exemplo, na XIX Sessão Ordinária, realizada em setembro de 2009, discutiu-se a proposta de pedido de informe sobre o histórico e o andamento das negociações para o Acordo de Associação Mercosul-União Europeia (MEP 185/2009) ${ }^{15}$. Tal nota era consequência das atividades relativas às negociações desenvolvidas no âmbito da delegação externa do Parlasul na Assembleia Parlamentar Euro-Latinoamericana (EuroLat). Esse pedido justificou-se na ocasião pela necessidade de informações para a preparação dos parlamentares, tendo em vista a realização de reuniões ordinárias que seriam realizadas no mesmo ano, em outubro, de forma a constituir uma preparação de informações a serem apresentadas e debatidas com os pares europeus. Chamamos a atenção para o fato de que, durante a Cúpula de Madri no ano de 2010, as delegações governamentais dos dois blocos concordaram em reativar as negociações, ou seja, os parlamentares mostraram-se atentos e preocupados em se preparar para a eventualidade da retomada das negociações.

Todavia, o problema da falta de informações persiste. Em sessão de junho de 2014, o parlamentar Adrián Pérez encaminhou à Comissão de Assuntos Internacionais do Parlasul uma Proposta de Recomendação ao CMC na qual solicitava ampla difusão dos avanços das negociações entre os blocos ${ }^{16}$. Na mesma sessão foi aprovada uma Solicitação de Informe ${ }^{17}$, recordando a necessidade dessas informações com a retomada das negociações em 2010. Esses pedidos de informação dos parlamentares também revelam uma preocupação com a falta de poder decisório do Parlasul dentro do Mercosul, que também é uma reivindicação dos parlamentares, mas não encontra receptividade por parte dos governos. Durante a IV Sessão Especial (27 de abril de 2009), o parlamentar paraguaio Mario Paz Castaing afirmou a importância de tornar o Parlasul um órgão de codecisão na estrutura institucional do Mercosul, tendo poder de ratificar acordos internacionais ou de adesão de novos membros ${ }^{18}$. A mesma solicitação apareceu na Recomendação do Parlasul

15 O pedido foi aprovado. Parlamento del Mercosur - XIX Sesión Ordinaria (21 de setiembre de 2009); MERCOSUR/PM/SO/PEDIDO DE INFORME 01/2009. Disponível em: <https://www. parlamentomercosur.org/innovaportal/file/7345/1/xix-sesion-ordinaria-del-parlamento-delmercosur-210909.pdf> e em: <https://www.parlamentomercosur.org/innovaportal/file/7345/1/pedido-deinforme-01-2009.pdf >. Acesso em: 2 maio 2018.

$16 \mathrm{MEP} / 30 / 2014$. Disponível em: <https://www.parlamentomercosur.org/innovaportal/file/8608/1/pedidode-infome-01-2014.pdf>. Acesso em: 2 maio 2018.

17 Pliego de Asuntos Entrados XXX Sesión Ordinária - 9 de junio de 2014. Disponível em: <https://www. parlamentomercosur.org/innovaportal/file/8608/1/pliego-de-asuntos-entrados-xxX-so.pdf>. Acesso em: 2 maio 2018.

18 Parlamento del Mercosur - IV Sesión Especial. Disponível em: <https://www.parlamentomercosur.org/innovaportal/file/8976/1/version-taquigrafica-iv-s.e..pdf>. Acesso 
enviada em novembro de 2016, que reivindicava: informar ao parlamento o conteúdo das ofertas; ativar o mecanismo do Ganrel (Grupo de Alto Nível sobre a Relação Institucional entre o CMC e o Parlamento do Mercosul); dispor de mecanismos para a participação concreta do Parlasul nas negociações ${ }^{19}$.

Nas palavras do parlamentar paraguaio Bernal Amarilla, "cuando se nos pregunta respecto al avance de las negociaciones con la Unión Europea, no tenemos datos oficiales, ciertos, para responder a nuestra gente" 20 . Percebe-se, portanto, uma tentativa por parte dos parlamentares tanto de criar mecanismos de pressão e comunicação nas negociações como de dotar de maior importância o órgão parlamentar. Essa discussão expressa o reconhecimento da exclusão desses parlamentares das decisões centrais da integração e de seu papel marginal no processo de negociação (Mariano, Bressan e Luciano, 2016, 2017).

Porém, o interesse direto dos parlamentares também pode ser lido como mais pragmático: a representação de setores produtivos específicos da sociedade. Essa lógica fica perceptível em Projetos de Disposição e Recomendação que citam setores produtivos específicos como a indústria de calçados e exportação de carne de patos $^{21}$ como interessados na reativação ou aceleração das negociações. Por exemplo, na sessão de 28 de junho, o parlamentar brasileiro Renato Molling efetuou a proposta de recomendação ao CMC para trabalhar com vigor na formação do acordo entre Mercosul e UE, dando especial atenção à isenção de taxas para o setor de calçados ${ }^{22}$.

Além disso, o tema das negociações surge, sobretudo, em decorrência dos debates no âmbito das negociações da Rodada Doha da OMC. Dessa forma, a questão dos subsídios agrícolas, que é vista como um entrave tanto para as negociações no âmbito da OMC como para aquelas referentes ao Mercosul-UE, gera o cruzamento das discussões parlamentares, especialmente quando as negociações de Doha não avançavam. Nesse contexto, o Parlasul considerava como fundamental um debate político com a UE, visando à concretização do acordo 23 .

Outro exemplo interessante de ser analisado é a interligação feita por alguns parlamentares entre a Questão das Malvinas e as negociações, como na sessão de 2 de

em: 2 maio 2018.

\footnotetext{
19 Mercosur/PM/SO/REC.23/2016c. Disponível em: <https://www.parlamentomercosur.org/innovaportal/file/12884/1/rec-23-2016.pdf>. Acesso em: 2 maio 2018.

20 Parlamento del Mercosur XLIII Sesión Ordinaria 7 de noviembre de 2016. Disponível em: <https://www. parlamentomercosur.org/innovaportal/file/12884/1/xliii-s.o-7-de-noviembre-de-2016.pdf >. Acesso em: 2 maio 2018

21 Propuesta de Recomendación - 12/2011/RE/XXVIII SO - MEP/44/2011. Disponível em: <https://www.parlamentomercosur.org/innovaportal/file/8019/1/pliego-de-asuntos-entrados-xxviiiso.pdf $>$. Acesso em: 2 maio 2018.

22 Propuesta de Recomendación - 36/2008/RE/SO. Disponível em: <https://www.parlamentomercosur.org/innovaportal/file/7493/1/anexo-iii.pdf>. Acesso em: 2 maio 2018.

23 Proyecto de Disposición - Acuerdo de Asociación Birregional Mercosur -Unión Europa. Disponível em: <https://www.parlamentomercosur.org/innovaportal/file/7493/1/46-2008-di.pdf>. Acesso em: 2 maio 2018.
} 
dezembro de 2011, quando se aprovou a Proposta de Recomendação cujo conteúdo recobra, justamente, a necessidade de que, em qualquer negociação internacional, a questão das Malvinas seja pontuada nos termos do acordo ${ }^{24}$. Nesse caso, o cruzamento das discussões parece ocorrer de forma estratégica pelos parlamentares, utilizando as negociações como mecanismo de pressão para resolução de outras questões, como no caso das Malvinas.

Por fim, as próprias discussões sobre o desenvolvimento do processo de integração do Mercosul trouxeram à tona o tema do acordo Mercosul-UE. Quando os parlamentares debateram a consolidação da Tarifa Externa Comum (TEC) ou a eliminação de sua dupla cobrança (e mesmo sobre a consolidação da União Aduaneira), seus discursos chamaram a atenção para a relação entre essas questões e as negociações com a UE, pois consideram que estas afetam as negociações entre os blocos ${ }^{25}$.

Independentemente da forma como o tema das negociações Mercosul-UE apareceu nos trabalhos do Parlasul, podemos afirmar que houve uma predisposição favorável a um acordo com o bloco europeu. Diferentemente do que ocorreu com a Alca, que provocou mobilização contrária da sociedade civil, dos sindicatos, dos setores econômicos, dos parlamentares e dos partidos políticos (Vigevani e Mariano, 2005) ${ }^{26}$, no caso das negociações com a Europa as resistências apareceram de forma mais pontual. Essa disposição em negociar o acordo com a UE não elimina as desconfianças e incertezas dos parlamentares em relação às consequências de sua implementação. O principal problema para os parlamentares é a falta de informação sobre o que está sendo negociado, como apontamos anteriormente.

É interessante notar também que o tema ganhou força nos momentos de crise econômica como uma saída possível para aliviar os problemas dos países e amenizar as situações de instabilidade política decorrentes. Em setembro de 2015, foi enviada à apreciação da Comissão de Assuntos Econômicos ${ }^{27}$ outra Proposta de Declaração pelo parlamentar Sergio Bergman, na qual o Parlasul cobrava a reativação das negociações. A proposta recordou que a UE e seus Estados membros são os maiores investidores estrangeiros na região. Destacava que outros países latino-americanos - como Chile, México, Peru, Colômbia e Equador - já possuíam acordos com o bloco europeu, debilitando a presença comercial do Mercosul, além de abrir precedentes para que países do bloco

\footnotetext{
24 Mercosur/PM/ACTA SPREP/01/2011; MERCOSUR/PM/SP/REC.01/2011. "SOLUCIÓN PACÍFICA PARA EL PROBLEMA DE LAS ISLAS MALVINAS"; Parlamento del Mercosur XIII Sesión Extraordinaria 10 de noviembre de 2014. Disponível em: <https://www.parlamentomercosur.org/innovaportal/file/9017/1/3-acta-aprobadapor-el-pleno.pdf>. Acesso em: 2 maio 2018.

25 III Sesión Ordinaria - Lunes 25 de junio de 2007. Disponível em: <https://www. parlamentomercosur.org/innovaportal/file/7486/1/v.t.-iii-s.o.pdf>. Acesso em: 2 maio 2018. $26 \mathrm{MEP} / 183 / 2014 \mathrm{c}$. Disponível em: <https://www.parlamentomercosur.org/innovaportal/file/9112/1/mep183-2014.pdf>. Acesso em: 2 maio 2018.

27 XXXIV Sesión Ordinaria - 21 de setiembre de 2015. Disponível em: <https://www.parlamentomercosur.org/innovaportal/file/10108/1/xxxiv-so-de-21-set-2015.pdf>. Acesso em: 2 maio 2018.
} 
queiram negociar de maneira bilateral28.

Isso é perceptível com a retomada das negociações em 2016, embora não por causa do apelo dos parlamentares do Parlasul, mas devido às mudanças políticas na Argentina e no Brasil. Em ambos os casos, o cenário político mostrou-se desfavorável desde 2015, quando o processo eleitoral argentino apontava a fragilidade do governo de Cristina Fernández de Kirchner (o que resultou na vitória de Mauricio Macri, da oposição) e a presidente brasileira Dilma Rousseff encontrava-se em meio a acusações de fraude eleitoral e ameaça de impeachment. Mesmo nesse contexto desfavorável, o Parlasul defendeu a retomada das negociações com a UE.

Apesar desse apoio, existem algumas declarações contra as negociações por parte de parlamentares venezuelanos, que são mais enfáticas. O venezuelano Yul Jabour ${ }^{29}$, então presidente da Comissão de Assuntos Internacionais do Parlasul, em novembro de 2014, afirmou que o parlamento deveria propor recomendações ao CMC para que o bloco estabelecesse ações que reduzissem a participação de potências neocoloniais no financiamento de projetos da região. Outro parlamentar venezuelano, Saúl Ortega, expresidente do Parlasul, em agosto de 2015, declarou que não seria com negociações de livre comércio com EUA, UE ou Aliança do Pacífico que o Mercosul se consolidaria. Em sua visão, a base social e política é a parte fundamental do bloco ${ }^{30}$.

Ressaltamos essas críticas dos parlamentares venezuelanos porque a retomada das negociações a partir de 2010 foi impulsionada pela percepção de que a incorporação da Venezuela seria um fator complicador ao processo negociador, o que de fato ocorreu. Ainda que o Parlasul não tenha poder de vetar ou interferir nas negociações, essa postura crítica venezuelana alimentou a oposição ao acordo, e explica a necessidade de os países suspenderem a sua participação no Mercosul a partir de 2018, como forma de aumentarem a probabilidade de concluir as negociações ainda nesse ano; o que não se concretizou.

De modo geral, ao longo dos anos, o Parlasul apresentou uma postura autônoma e ativa em seu posicionamento quanto às negociações, no entanto, os níveis de transparência das negociações birregionais permanecem baixos e os parlamentares reforçam continuamente pedidos de maior acesso às informações. Além disso, não há grande polarização nos debates relativos ao acordo, tendo em vista que grande parte dos parlamentares tem apoiado o andamento das negociações com a UE, excetuando posicionamentos mais específicos de alguns membros, como ficou perceptível em alguns casos de parlamentares venezuelanos.

28 MEP/110/2015b. Disponível em: <https://www.parlamentomercosur.org/innovaportal/file/10108/1/362015-de-xxxiv---mep-110-2015.pdf>. Acesso em: 2 maio 2018.

29 XIII Sesión Extraordinaria del Parlamento del Mercosur. Disponível em: <https://www.parlamentomercosur.org/innovaportal/file/9129/1/xiii-se-de-10-nov-2014.doc>. Acesso em: 2 maio 2018.

30 MERCOSUR/PM/ACTA/SP 05/2015a ANEXO IV. Disponível em: $<$ https://www.parlamentomercosur.org/innovaportal/file/9897/1/anexo-iv---palabras-del-presidente-delpm.pdf >. Acesso em: 2 maio 2018. 


\section{Conclusão}

Tendo como pano de fundo o acordo comercial Mercosul-UE, a análise sobre o envolvimento do Parlamento Europeu e do Parlamento do Mercosul nessas negociações ressaltou três aspectos para entender o papel parlamentar nesse acordo de associação: autonomia, transparência e polarização. Apesar das reconhecidas diferenças com relação a suas competências, esse exercício comparado permitiu identificar elementos significativos sobre o desempenho dos dois parlamentos no acompanhamento do acordo comercial em questão. No caso europeu, não obstante o PE geralmente assumir uma posição favorável aos acordos comerciais, isso não significa que o Parlamento não possa construir uma posição autônoma com relação à postura da Comissão Europeia em acordos de comércio. O exemplo das negociações Mercosul-UE demonstrou que o PE não está somente seguindo a posição negociadora da Comissão, mas também inclui suas próprias preocupações nas negociações, especialmente relacionadas à inclusão de temas de direitos humanos e proteção enfática do setor agrícola europeu.

Uma agenda autônoma também está presente no caso do Parlasul, embora reconheçamos suas limitações enquanto instância consultiva do Mercosul. Além das questões comerciais, que são o centro das atenções dos parlamentares, encontramos em seus debates preocupações e temas que não fazem parte da agenda de negociações dos governos nesse acordo. Certamente, o melhor exemplo disso é a preocupação com a inclusão da questão das Malvinas, pois, como apontamos anteriormente, esse parlamento aprovou uma proposta de recomendação segundo a qual esse tema deve ser inserido em qualquer negociação internacional empreendida pelo Mercosul com seus pares europeus.

Essa agenda autônoma acaba também servindo como um elemento de barganha por parte dos governos, que resgatam questões apontadas pelos parlamentares para reforçar sua posição nas negociações. Um exemplo claro disso foi a utilização do questionamento da legitimidade do governo brasileiro no caso do impeachment da presidente Rousseff. Esse novo posicionamento dos países do Mercosul permitiu a aproximação dos dois blocos e a retomada efetiva das negociações, apesar de gerar certo desconforto aos negociadores europeus quando cerca de 30 deputados de dois grupos políticos do Parlamento Europeu (verdes e Esquerda Unida Europeia) sugeriram à alta representante para Assuntos Externos, Federica Mogherini, que as negociações MercosulUE deveriam ser suspensas em retaliação ao "golpe político" perpetrado para a remoção da presidente eleita (El País, 2016). Apesar de esses posicionamentos não necessariamente serem absorvidos pela Comissão Europeia, eles de certa forma influem nos trabalhos de negociação porque reforçam questionamentos realizados por países contrários ao acordo, ou mesmo argumentos dos negociadores europeus que, diante dessas críticas, pressionam os parceiros do Mercosul a ceder mais para compensar o desgaste que a negociação traz ao bloco europeu. 
O outro aspecto analisado pelo artigo foi a questão da transparência, que está intimamente ligada ao acesso às informações sobre o andamento das negociações. Embora existam diferenças de competências marcantes entre os dois parlamentos na aprovação dos acordos comerciais, em ambos os casos encontramos insatisfações em relação a esse quesito. Nesse sentido, é interessante observar que, mesmo no caso do PE, existem obstáculos importantes quanto à transparência dessas negociações. Em comparação às negociações comerciais com os Estados Unidos (TTIP), os eurodeputados e os oficiais do PE têm constantemente reclamado do baixo grau de transparência das negociações Mercosul-UE. Embora trocas de ofertas tarifárias entre os dois blocos já tenham sido realizadas, o PE ainda não recebeu acesso significativo aos termos específicos dessas negociações. Também se observa uma preocupação significativa a respeito do acesso a documentos confidenciais, os quais facilitariam o escrutínio da posição negociadora do lado europeu.

Esse ponto também é um tema de constante reclamação no caso do Parlasul, mas não somente em relação às negociações Mercosul-UE. A falta de informação é recorrente nas falas dos deputados do Parlasul, que, em seus pronunciamentos, solicitam tanto o acesso às informações como a própria possibilidade de poder participar diretamente nas negociações. Essa questão está ligada à debilidade dessa instituição dentro do Mercosul, pois, ao ter apenas um papel consultivo, se vê alijada do processo decisório da integração e sem possibilidade de exercer adequadamente o seu papel de representante dos interesses sociais, especialmente no caso dos parlamentares diretamente eleitos. Portanto, no caso do Parlasul, as declarações dos deputados sobre a necessidade de mais informação e transparência revelam também uma preocupação com sua função institucional.

Analisando comparativamente os dois casos, percebemos que, embora ambos demonstrem autonomia no que se refere aos debates e agendas, quando a questão trata de capacidade de influir/acompanhar o processo decisório, há uma similitude de comportamento das instâncias executivas (negociadoras): o não repasse de informações. Mas a semelhança termina nesse quesito, já que, no caso europeu - devido às mudanças produzidas pelo Tratado de Lisboa -, esses parlamentares terão oportunidade de se manifestar e posicionar em relação à aprovação do acordo na fase de sua ratificação, o que não ocorrerá no caso do Parlasul, confirmando a premissa apresentada no início do artigo.

Finalmente, o último aspecto considerado foi a polarização, evidenciada pelo posicionamento dos grupos políticos e parlamentares individuais. Observamos que, enquanto as posições dos grupos políticos são mais evidentes no caso do PE, o que se conecta a sua tradição de organização em famílias políticas transnacionais, no Parlasul prima-se pelo posicionamento individual dos parlamentares em suas declarações a respeito das negociações Mercosul-UE, o que demonstra a falta de aprofundamento e coesão das bancadas transnacionais nesse parlamento. No entanto, também foram encontradas conexões entre os parlamentares e os partidos nacionais ou nacionalidades específicas, os 
quais têm apresentado opiniões mais sensíveis em relação ao acordo. A saber, no caso do $\mathrm{PE}$, parlamentares franceses e irlandeses de partidos políticos ideologicamente distintos têm demonstrado grande preocupação com o acordo por conta do tema da agricultura. Ao mesmo tempo, no Parlasul os parlamentares venezuelanos ligados ao chavismo foram os mais reticentes a essas negociações.

Nesse sentido, identificamos na análise dos posicionamentos dos deputados europeus um importante grau de polarização sobre as negociações da UE com o Mercosul. Ainda que padrões gerais dos grupos políticos europeus sobre acordos comerciais sejam observados no caso analisado - apoio dos liberais, conservadores e democratas-cristãos aos acordos, forte resistência dos verdes e da Esquerda Unida, e posição dúbia dos socialistas -, parlamentares de países específicos, como França e Irlanda, de diferentes bandeiras políticas pressionaram por uma posição mais defensiva da Comissão com relação aos setores de carne e agricultura. Distintamente da postura mais técnica e burocratizada da Comissão Europeia nos acordos comerciais, o PE tem assumido uma posição muito mais política e polarizada ante os acordos comerciais negociados pela UE por meio dos grupos políticos europeus, reflexo da pluralidade ideológica encontrada nas fileiras desse parlamento supranacional.

A análise sobre polarização no caso do Parlasul é interessante porque, ao contrário do que se poderia esperar, percebe-se um posicionamento bastante favorável às negociações. Como demonstramos em nossa reconstrução das negociações, o acordo com a União Europeia apresenta grande similitude com as negociações sobre a Alca, mas, diferentemente desta última, não gerou nos grupos políticos, econômicos e sociais de oposição ao acordo a mesma mobilização, que, no caso da Alca, envolveu manifestações populares e amplos debates nos congressos nacionais. No caso das negociações com a UE, a oposição dentro do Parlasul ao acordo é bastante marginal e específica: são os parlamentares antiglobalização e, portanto, contrários a todo tipo de acordo comercial, encontrados na bancada chavista da Venezuela (embora esse país não participe das negociações), e os da esquerda radical dos demais países.

Esse comportamento diferenciado em relação ao que ocorreu com as negociações da Alca pode ser explicado tanto pela lógica política interna como pela institucionalidade regional. No caso da política interna, os partidos que se opuseram à Alca pertenciam ao campo político de esquerda, ao qual, no momento de retomada das negociações com a UE, se vinculavam os governos que estavam impulsionando esse processo. Assim, apesar de o acordo com os europeus ser semelhante em conteúdo ao que estava sendo negociado com os EUA, não poderia ser tão fortemente criticado pela base parlamentar de apoio dos governos mercossulinos. A exceção a essa situação foi o governo de Hugo Chávez, que se mostrou crítico ao acordo entre os blocos e, por isso mesmo, a incorporação da Venezuela ao Mercosul foi considerada como um elemento complicador e os parlamentares venezuelanos posicionaram-se como opositores. 
No aspecto da institucionalidade regional, é importante destacar que a marginalização do Parlasul dentro do bloco não se refere apenas à sua não participação no processo decisório e à sua dificuldade em acessar as informações necessárias, mas também ao próprio funcionamento dessa instituição. Não há, por parte dos parlamentares que o compõem um compromisso e envolvimento plenos, isto é, aqueles que são indicados pelos congressos nacionais (delegações brasileira, uruguaia e venezuelana) apresentam um grau de participação muito limitado porque priorizam suas atividades no âmbito nacional, sem contar a impossibilidade de uma presença mais constante, com o Parlasul tendo sessões apenas um dia por mês.

Por parte dos parlamentares exclusivos que foram diretamente eleitos (argentinos e paraguaios), o envolvimento também é baixo porque, apesar de sua situação diferenciada, tampouco estão presentes permanentemente no Parlasul, pois este permanece sem atividade na maior parte do tempo. Com esse modo de funcionamento, há pouco espaço para a interação, o diálogo e a construção de uma maior articulação política entre os deputados do Parlasul, tal como ocorre no caso europeu. Outro ponto a ser destacado nesse caso é a não ocorrência de um processo de acúmulo de informação, que seria fundamental para a construção de um posicionamento por parte dos parlamentares em relação a essa negociação.

Questões importantes, como a negociação comercial entre os dois blocos, poderiam ser um elemento de estímulo para que os parlamentares mercossulinos buscassem ampliar sua capacidade decisória ou para aumentar seu envolvimento, já que suas falas revelam a consciência de que possuem um engajamento limitado.

Nesse ponto, a comparação com o caso europeu pode ser usada como parâmetro relevante para pensar em estratégias alternativas que possam promover a superação de suas limitações. No entanto, o Parlasul parece caminhar no sentido contrário, tendo em vista que a mais recente decisão dos Estados membros foi justamente suspender as eleições diretas para a escolha de seus representantes, o que pode fragilizar ainda mais os instrumentos que os deputados estão empregando para acompanhar essas negociações.

\section{Referências bibliográficas}

AMORIM, C.; PIMENTEL, R. Iniciativa para as Américas: o acordo do Jardim das Rosas. In: Albuquerque, J. A. (org.). Sessenta anos de política externa brasileira (1930-1990). Vol. II. São Paulo: Cultura/Nupri - USP/Fapesp, 1996.

BÖRZEL, T.; RISSE, T. Three cheers for comparative regionalism. In: BÖRZEL, T.; RISSE, T. (eds.). The Oxford Handbook of comparative regionalism. Oxford: Oxford University Press, 2016.

BOYeR, I.; SChUSChNY, A. Quantitative assessment of a free trade agreement between Mercosur and the European Union. Série Estudios Estadísticos y Prospectivos, no 69, Statistics and Economic Projections Division Natural Resources and Infrastructure Division. Cepal: Santiago de Chile, 2010.

CAMPos. C. "O empoderamento do Parlamento Europeu no controle da Comissão Europeia: os casos 
KARINA L. PASQUARIELLO MARIANO; BRUNO THEODORO LUCIANO; LUCAS BISPO DOS SANTOS

Santer (1995-1999) e Barroso (2004-2009)". Opinião Pública, vol. 23, no 2, p. 509-536, maio-ago., 2017.

CAPoraso, J.; MARKS, G.; MoraVcsik, A.; PollaCK, M. "Does the European Union represent an $\mathrm{n}$ of 1?". ECSA Review, vol. 10, no 3, 1997.

Cienfuegos, M. "La asociación estratégica entre la Unión Europea y el Mercosur, en la encrucijada". Documentos Cidob. Série América Latina, nº 15, 2006.

COMISSÃo EUROPEIA. "Instrumento de Cooperação para o Desenvolvimento (ICD) 2014-2020: Programa Indicativo Plurianual Regional para a América Latina", 2014. Disponível em: <http://ec.europa.eu/europeaid/node/100251_en>. Acesso em: 20 jul. 2017.

DEUTSCHE BANK. "Research talking point. Brics \& G-3. Changing interaction, emerging complementarities". Frankfurt, 2011.

DRI, C.; PAIVA, M. "Parlasul, um novo ator no processo decisório do Mercosul?". Revista de Sociologia e Política, vol. 24, no 57, p. 31-48, mar. 2016.

EL PAÍs. "Grupo de deputados europeus pede suspensão das negociações com o Mercosul". 31 maio 2016. Disponível em:

<https://brasil.elpais.com/brasil/2016/05/31/internacional/1464656635_863477.html>. Acesso em: 11 jun. 2019.

FLÔRES, R. O alargamento da União Europeia e as negociações Mercosul-EU: uma nota preliminar. In: FLÔRES, R.; MARCONINI, M. (eds.). Acordo Mercosul-União Europeia: além da agricultura. Rio de Janeiro: Konrad Adenauer Stiftung, 2003.

HiRST, M.; LIMA, M. R. S.; PINHEIRO, L. "A política externa brasileira em tempos de novos horizontes e desafios". Nueva Sociedad, p. 22-41, dez. 2010.

KEGEL, P.; AMAL, M. "Perspectivas das negociações entre o Mercosul e a União Europeia em um contexto de paralisia do sistema multilateral e da nova geografia econômica global". Revista de Economia Política, São Paulo, vol. 33, no 2, p. 341-359, 2013.

KRePPEL, A. The European Parliament and supranational party system: a study in institutional development. Cambridge University Press, 2002.

Mariano, K. L. P. Regionalismo na América do Sul. São Paulo: Cultura Acadêmica, 2015.

MARIANO, K. L. P.; BRESSAN, R. N.; Luciano, B. T. Integração com democracia: o desafio para os parlamentos regionais. Rio de Janeiro: Fundação Konrad Adenauer, 2016.

. "A comparative reassessment of regional parliaments in Latin America: Parlasur, Parlandino and Parlatino". Revista Brasileira de Política Internacional, vol. 60, no 1, p. 1-18, 2017.

MARIANO, M. P.; RAMANZINI JR., H. "Brazil and the G-20: domestic pressures and the construction of the negotiating position in the Doha round of the WTO". Journal of World Trade, vol. 47, n' 6, p. 1.203-1.224, 2013.

Parlamento do Mercosul. "Protocolo Constitutivo do Parlamento do Mercosul", 2005.

"Anexo III; Pliego de Asuntos Entrados. X Sesión Ordinaria", Mercosur/PM/ACTA 09/2008, Montevidéu, 30 jun., 2008a.

$2008 b$.

"Proyecto de Disposición. Acuerdo de Asociación Birregional Mercosur-Unión Europea", 
PARLAMENTOS REGIONAIS NAS NEGOCIAÇÕES COMERCIAIS: O PARLAMENTO EUROPEU E DO MERCOSUL

"Pedido de Informe Acuerdo de Asociación Mercosur-Unión Europea 01/2006", 2009.

"Acta de la Sesión Preparatoria 01/2011", Montevidéu, 2 dez., 2011.

"Anexo III; Lectura de Asuntos Entrados XXVIII Sesión Ordinaria. Propuesta de Actos Presentados", Mercosur/PM/ACTA/SO 01/2013, Montevidéu, 2013.

$2014 a$.

. "Pedido de informe Acuerdo de Asociación Mercosur-Unión Europea", Montevidéu,

Parlamento do Mercosul. "Pliego de Asuntos Entrados XXX Sesión Ordinaria", Montevidéu, 9 jun., 2014b.

. "Declaración del día de la Emancipación de los Pueblos Latinoamericanos.

MEP/183/2014", Montevidéu, 10 nov., 2014c.

"Anexo IV; Palabras del Presidente del Parlamento del Mercosur Saúl Ortega Campos", Mercosur/PM/ACTA/SP 05/2015, Montevidéu, 2015a.

. "Proyecto de Declaración. MEP/110/2015", Montevidéu, 17 set., 2015b.

. "Proyecto de Recomendación del Parlamento del Mercosur respecto de la Formulación de la oferta que el Mercosur llevará a las negociaciones por el Tratado de Libre Comercio con la Unión Europea. MEP/122/2016". 15 abr., $2016 a$.

"Formulación de la oferta que el Mercosur llevará a las Negociaciones por el Tratado de Libre Comercio con la Unión Europea", Mercosur/PM/SP/REC.12/2016, Montevidéu, 12 ago., 2016 b.

"Participación activa del Parlasur en las negociaciones con la Unión Europea (UE)", Mercosur/PM/SO/REC.23/2016, Montevidéu, 7 nov., 2016c.

PARLAMENTO EuROPEU. "European Parliament resolution on economic and trade relations between the $\mathrm{EU}$ and Mercosur with a view to the conclusion of an Interregional Association Agreement", 2006/2035(INI), 2006.

Release, 24 maio 2011.

"European Parliament resolution of 17 January 2013 on trade negotiations between the EU and Mercosur", 2012/2924(RSP), 2013.

. "Letter to commissioner for Trade, Subject: access to TTIP-related documents comprehensive agreement on operational arrangements between the Inta Committee and DG Trade", 10 dez., 2015.

"Report on a new forward-looking and innovative future strategy for trade and investment", 2015/2105(INI), 2016.

PHELAN, W. "What is sui generis about the European Union? Costly international cooperation in a selfcontained regime". International Studies Review, vol. 14, n 3, p. 367-385, 2012.

Rittberger, B. "The creation and empowerment of the European Parliament". JCMS, vol. 41, no 2, p. 203-225, 2003.

SARAIVA, M. "A União Europeia como ator internacional e os países do Mercosul". Revista Brasileira de Política Internacional, vol. 47, no 1, p. 84-111, 2004.

SAVINI, M. "As negociações comerciais entre Mercosul e União Europeia". Revista Brasileira de Política 
KARINA L. PASQUARIELLO MARIANO; BRUNO THEODORO LUCIANO; LUCAS BISPO DOS SANTOS

Internacional, vol. 44, no 2, p. 109-125, 2001.

ShAOHUA, Y. "The European Parliament's role in EU trade policy after Lisbon: analysis from an actorness approach". Online Papers on Parliamentary Democracy, vol. 3, 2015.

SILVA-RÊGo, B. F.; FIgUeIRA, A. R. "The economic face of international co-operative arrangements: the cases of IBSA and CPLP". Contexto Internacional, vol. 40, no 1, 2018.

SöDERBAUM, F. Rethinking regionalism. Londres: Palgrave Macmillan, 2015.

StAVRIdis, S.; Ajenjo, N. "EU-Latin American parliamentary relations: some preliminary comments on the Eurolat". Jean Monnet/Robert Schuman Paper Series, vol. 10, nº 3, abr. 2010.

TOMAZINI, R. "As negociações para o estabelecimento de um acordo de associação entre a União Europeia e o Mercosul e as percepções do empresariado". Século XXI, vol. 2, no 1, p. 73-88, 2011.

VALLE, V. M. "O peso das relações inter-regionais com a União Europeia em relação a outras alternativas de política externa do Mercosul". Revista Brasileira de Política Internacional, vol. 48, no 1 , p. 99-128, 2005.

VAn den Putte, L.; De Ville, F.; Orbie, J. "The European parliament's new role in trade policy: turning power into impact". CEPS Special Report, no 89, maio 2014.

VentuRA, D. As assimetrias entre o Mercosul e a União Europeia: os desafios de uma associação inter-regional. São Paulo: Manole, 2003.

Vigevani, T.; Mariano, M. "A Alca e a política externa brasileira". Cadernos Cedec - Centro de Estudos de Cultura Contemporânea. São Paulo: Cedec, 2005.

\begin{abstract}
Regional parliaments in trade negotiations: the involvement of the European and Mercosur Parliaments in the EU-Mercosur negotiations

The EU-Mercosur negotiations have been traditionally assessed from the perspective of the governments. The aim of this article is to discuss the role of regional parliaments in these negotiations, which already have endured for over twenty years. The analysis verifies whether the existence of a regional parliament has amplified the discussions over the negotiations and has impacted the progress of the trade talks, taking into account the period between 1999 and 2017. The article analyzes the positions of parliamentarians with regard to: the proposals presented by each bloc; the degree of information on negotiations to which they have access; and the capacity of regional parliaments to influence the terms of the agreement. The objective was to verify the degree of involvement of regional parliaments in trade negotiations. We conclude that, although the two parliaments present distinct degrees of competence, in both cases autonomous performance regarding the governments, with a significant degree of political polarization with regards to the outcomes of the agreement and a strong demand for more transparent trade negotiations, was observed.
\end{abstract}

Keywords: trade negotiations; European Union; Mercosur; European Parliament; Mercosur Parliament

\title{
Resumen
}

Parlamentos regionales en las negociaciones comerciales: el envolvimiento de los Parlamentos Europeo y del Mercosur en las negociaciones UE-Mercosur

Las negociaciones Mercosur-UE se analizan tradicionalmente por la perspectiva de los gobiernos. El objetivo de este artículo es discutir el papel y relevancia de los parlamentos regionales en esas negociaciones que duran más de veinte años. El análisis verifica si la existencia de un parlamento regional amplía las discusiones sobre las negociaciones e influye en el progreso de las mismas, considerando el período entre 1999 y 2017. El artículo analiza las posiciones de los parlamentarios en 
relación a las propuestas presentadas por los respectivos bloques, información sobre las negociaciones a las que efectivamente tienen acceso, y la capacidad de influencia de los parlamentarios regionales en virtud del acuerdo. El objetivo fue verificar el grado de participación de los parlamentos regionales en las negociaciones comerciales. Se concluye que, aunque los dos parlamentos tienen grados de competencia bastante diferentes, en ambos casos existe una actuación autónoma con relación a los gobiernos, con un grado de polarización política significativa con respecto al resultado del acuerdo y una fuerte demanda por negociaciones comerciales más transparentes.

Palabras clave: negociaciones comerciales; Unión Europea; Mercosur; Parlamento Europeo; Parlamento del Mercosur

\section{Résumé}

Parlements régionaux dans les négociations commerciales: L'implication du Parlement Européen et du Mercosur dans les négociations entre I'Union Européenne et le Mercosur

Les négociations entre le Mercosur et l'UE sont traditionnellement analysées du point de vue des gouvernements. L'objectif de cet article est de discuter du rôle et de la pertinence des parlements régionaux dans ces négociations de plus de 20 ans. Nous examinons si l'existence d'un parlement régional élargit les discussions sur les négociations et influe sur leurs progrès, en tenant compte de la période 1999-2017. Les positions des parlementaires sont également analysées par rapport aux propositions avancées par les blocs respectifs, au degré d'information sur les négociations auxquelles ils ont réellement accès et à la capacité des parlementaires régionaux à influencer l'accord. L'objectif est de vérifier le degré d'implication des parlements régionaux dans les négociations commerciales. On en conclut que, bien que les niveaux de compétence des deux parlements soient assez différents, il existe dans les deux cas une action autonome en ce qui concerne les gouvernements, qui présente une certaine polarisation politique quant à l'issue de l'accord et une forte demande de négociations commerciales plus transparentes.

Mots-clés: négociations commerciales; Union Européenne; Mercosur; Parlement Européen; Parlement du Mercosur

Artigo submetido à publicação em 16 de novembro de 2018. Versão final aprovada em 5 de junho de 2019.

Opinião Pública adota a licença Creative Commons CC-BY. 